\title{
Enhancement of Open-Pit Mining Efficiency by Means of Quality Improvement of Open-Pit Excavators Design and Operating In Specified Conditions
}

\author{
Pyotr Zykov ${ }^{1, *}$, Evgeny Zvarych ${ }^{1}$, Andrei Karasev ${ }^{1}$, and Dieter Weber $^{2}$ \\ ${ }^{1}$ T.F. Gorbachev Kuzbass State Technical University, Novokuznetsk branch, 654000 Novokuznetsk, \\ Russian Federation \\ ${ }^{2}$ Czech Technical University in Prague, 16636 Zikova 1903/4, Praha, Czech Republic
}

\begin{abstract}
The objective set in the research is the following: to develop the methodology and application tools for assessment of the open-pit excavators engineering level when selecting and designing them for specific mining-geological and technical service conditions. To achieve the objective, the methods of statistical data analysis, methods of regression models and of mathematical experimentation building, analysis and synthesis, methods of comprehensive assessment of the engineering level indicators, as well as mathematical modeling and appliance of linear algorithm were used. As a result, there was developed the methodology of comprehensive assessment of engineering level and parameters optimization of open-pit shovel excavators, there was also developed a software package, based on the methodology mentioned above, that allows science-based selection of excavators that possess optimum parameters for the specified conditions.
\end{abstract}

\section{Introduction}

Open-pit shovel excavators are the prime extracting equipment used for open-pit works and they perform over $80 \%$ of the total work content. In this regard, quality of their performing functions determines to a greater extent the efficient operation of the whole mining enterprise $[1,2]$.

Currently there is a process of technical re-equipping of the out-of-date excavator fleet by the new generation of extraction-and-loading machines implementation, as a rule such new machines have a hydraulic drive. Mining specialists' selection of excavators is mainly based on the operating history of the previous machines, their price and operation costs, and, what is more, no quality assessment of the machines in specific conditions of the enterprise is performed. Such approach has lots of disadvantages the main one is that it is impossible to «bind» the parameters of the selected machine and the parameters of the environment. As a result such approach does not lead to significant improvement of

*Corresponding author: zykovpetr@yandex.ru 
excavator performance quality. When selecting and designing machinery with necessary relevant parameters it is necessary to use systems approach that will help improve the quality of open-pit excavation equipment performance.

Appliance of science-based range of methodologies that allow selecting or developing machines possessing optimum performance according to the quality criteria for specific mining conditions will make it possible to improve open-pit mining efficiency, to reduce costs of mining process, to increase excavator-car complex productivity. Development of software package, based on such range of methodologies, will make it possible to simplify and computerize the problem of excavator model selecting according to the specific conditions.

\section{Methods}

\subsection{The methodology of excavator performance assessment}

The assurance of required indicators of excavator performance in specific conditions according to engineering specifications, as well as production and operational requirements greatly depend on the quality of the excavation process performed by the excavator. The excavator quality can be displayed only during the process of performing its function according to its purpose, that is, during excavation of mined rock in specified operating conditions [1, 5-7]. The excavator mustn't be considered apart from the elements of the whole digging system «excavator-mined rock-human being-outside environment».

The main purpose of quality assessment of an excavator - developed mined rock human being - outside environment interaction, as the elements of the whole digging system, is to determine how efficiently each element functions in specified mininggeological and engineering conditions $[8,9]$. Quality assessment makes it possible to solve the problem of open-pit excavators selecting and designing according to specific mining plant conditions.

The conducted analysis of existing quality assessment techniques showed that the most acceptable analogue for the assessment of open-pit shovel excavators engineering level is G. I. Solod's methodology which he proposed in 1991.The methodology is based on the fundamental principles of qualimetry and allows conducting quantitative assessment of quality and engineering level of operationally non-varying machines of different types, dimensions types and structural designs.

\subsection{Methodology of excavator parameters optimization while designing}

Currently there are no sufficient normative-technical documents that specify such important direction of product quality improvement as its optimum design.

Each object of design has its own designation and like any other system it is characterized by its structure and parameters. The structure that defines the components of the object of design and their links, must guarantee the proper product operating and achieving the goals set according to its designation. Each component of the object of design is also characterized by its own parameters that are one way or other linked and are relevant to the object of design parameters. All these characteristics (the structure of the designed object, its parameters, the parameters of its components and their linkage) present the raw information necessary for the optimum design of the object.

For the purpose of the object parameters optimization it is necessary to create a formalized mathematical model. Mathematical model of optimization (MMO) consists of an objective function, restrictions and boundary conditions. The objective function presents 
mathematical description of reliance of the designed object application purpose on the parameters being optimized and in general term can be expressed as follows:

$$
P=f(P) \rightarrow \max (\min )
$$

where $P j-$ are the parameters being optimized $(j=1,2, \ldots ., m$, where $m$ is the number of the parameters being optimized).

Boundary conditions indicate maximum allowable values of variables. In general case boundary conditions are two-sided.

$$
b_{j} \geq P_{j} \geq a_{j}
$$

But often there is no upper boundary $b j-\left(b_{j} \rightarrow \infty\right)$, and the lower boundary $a j$ is equal to zero. Such boundary condition requires only so-called non-negative quantity for the parameter being optimized, that is $P_{j} \geq 0$.

Restrictions in MMO may present the descriptions of connections between parameters being optimized, formalization of expressions according to correspondence of actual indicators of designed object to the specified ones as well as formalization of additional purposes that were left beyond the objective function. Besides, the restrictions are introduced into MMO to reduce the dimension of optimization problem which is done to simplify problem statement and solving. The restrictions are expressed either in terms of relations that describe links between parameters being optimized:

$$
c_{j}=f_{c}\left(P_{j}\right) ; j=1,2, \ldots, m,
$$

or in terms of inequalities that describe different structural, operating and regulatory restrictions:

$$
H_{k}=f_{H}\left(P_{j}\right) ; k=1,2, \ldots, l
$$

In such a way, from the informative point of view the process of design of any object includes acquisition of raw information about the object of design, its parameters optimization performed on the ground of the objects purpose as well as making a decision based on the results optimization and presentation by the form of normative-technical documents. The documents serve the foundation for project translation into end products. It should be mentioned that under free market conditions state regulatory documents, that were widely used earlier, today lose their importance at large extent, so the normativetechnical documents mentioned above are developed by each customer with regard to their specific conditions and can be presented in the form of technical design specification.

\section{The Results}

\subsection{Development of the methodology of engineering level and optimization of open-pit shovel excavators parameters comprehensive assessment}

The basis of the methodology is the functional criterion of the machine that determines its main purpose. G. I. Solod proposed determining the criterion in the form of product of mining machine production capacity while performing its function in specific conditions and specific energy of the process of machine performing its function in such conditions. 
Thereunder, the functional criterion of the open-pit excavator quality assessment can be presented by the form of the following $(\mathrm{kJ} / \mathrm{h})$ :

$$
\lambda=P \cdot W,
$$

where $P$ - is estimated-theoretical production capacity of the excavator, $\mathrm{m}^{3} / \mathrm{h} ; W-$ specific energy of the mining rock excavation, $\left(\mathrm{kJ} / \mathrm{m}^{3}\right)$.

The expression for functional criterion calculation for shovel excavator of the «front shovel» type in the specific conditions $\left(\mathrm{kW} / \mathrm{m}^{3}\right)$ will take the following form:

$$
\lambda^{\prime}=\frac{3600 \cdot k_{u} \cdot k_{\varepsilon} \cdot k_{k \varepsilon}}{t_{u} \cdot k_{p}}\left[k_{f}+\frac{k_{u}}{k_{p}} \rho_{n} \cdot g\left(\frac{h_{\kappa}}{2}+\frac{\pi^{2}}{900 \cdot \alpha \cdot g}\left(n \cdot R_{\theta}\right)^{2}\right)\right],
$$

for the open-pit shovel excavators of «back-hoe» type:

$$
\lambda^{\prime}=\frac{3600 \cdot k_{u} \cdot k_{\theta} \cdot k_{k \varepsilon}}{t_{u} \cdot k_{p}}\left[k_{f}+\frac{k_{u}}{k_{p}} \rho_{n} \cdot g\left(\left(\frac{h_{k}}{2}+h_{6}\right)+\frac{\pi^{2}}{900 \cdot \alpha \cdot g}\left(n \cdot R_{6}\right)^{2}\right)\right],
$$

where $\alpha$ is a rotational angle of the unloading process, degrees; $h_{B}-$ maximum height of the unloading, $\mathrm{m} ; k_{H}$ - coefficient of bucket (shovel) full; $k \boldsymbol{P}$ - mining rock fragmentation coefficient; $k_{B}$ - excavator operation time coefficient; $k_{K B}$ - shovelman qualification and handling quality coefficient; $k_{f}$ - specific rock resistance to digging, $\mathrm{kPa} ; \rho_{n}-$ mining rock density, $\mathrm{t} / \mathrm{m}^{3} ; h_{K}-$ maximum excavator digging height, $\mathrm{m} ; n-$ swing speed, $\mathrm{rad} / \mathrm{s} ; R_{B}-$ maximum unloading radius, $\mathrm{m} ; t_{C}-$ cycle duration, $\mathrm{s} ; g-$ gravitational acceleration, $\mathrm{m} / \mathrm{s}^{2}$.

Excavator quality indicators are taken from the USSR's State Standard 4.377-85 and what is more, the indicators of purpose, reliability, technological effectiveness are of the greatest importance and other groups of indicators are not so important, this fact is connected with the chosen criterion. To reduce the number of values, some parameters may be translated into specific type (the advantage of any specific indicators is the following: they combine several absolute indicators) that completely corresponds to the principles of qualimetry.

By way of the indicators that determine engineering level of open-pit shovel excavators the following are suggested: specific energy density $\left(E_{y}\right)$; specific metal content $\left(k_{M}\right)$; specific excavator digging force $\left(k_{f}^{E}\right)$; specific maximum digging height and radius $\left(k_{p}^{h K}\right.$ and $\left.k_{p}{ }^{R K}\right)$; excavator service life $\left(T_{P}\right)$.

As a result, we have obtained a complex consisting of six indicators that determine the engineering level of open-pit shovel excavators (fig. 1). 


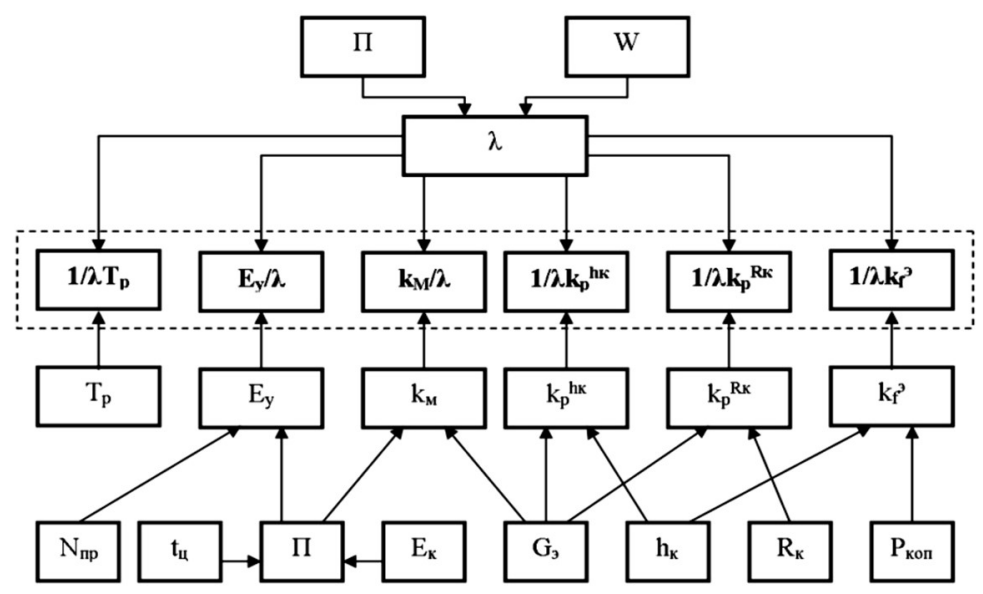

Fig. 1. The complex of indicators that determine engineering level of open-pit shovel excavators: $\lambda-$ functional criterion, $k J / h ; k_{f}^{E}$ - specific excavator digging force, MPa; $E_{Y^{-}}$specific energy density, $\mathrm{kW} /\left(\mathrm{m}^{3} / \mathrm{h}\right) ; k_{M}$ - specific metal content, $\mathrm{t} /\left(\mathrm{m}^{3} / \mathrm{h}\right) ; k_{p}{ }^{h \kappa}$ - specific maximum digging height; $k_{p}{ }^{R \kappa}-$ specific maximum digging radius; $T_{p}$ - service life, $\mathrm{h} ; P_{k o n}$ - specific digging force, $\mathrm{kH} ; N_{n p}-$ drive power, $\mathrm{kW} ; P$ - productive capacity, $\mathrm{m}^{3} / \mathrm{h} ; G_{E}$ - operation weight of the excavator together with operating equipment, $\mathrm{t} ; h_{K}$ - maximum digging height, $\mathrm{m} ; R_{K}$ - maximum digging radius, $\mathrm{m} ; t_{C}-$ theoretical cycle duration, $\mathrm{s} ; E_{K}$ - shovel capacity, $\mathrm{m}^{3} ; W$ - specific energy of mining rock excavation, $\mathrm{kJ} / \mathrm{m}^{3}$.

Composite indicator of excavator quality is determined in accordance to the algorithm methodology presented in figure 2 .

\subsection{Development of the methodology of excavator parameters optimization while designing}

On the basis of the systemic approach there was developed a mathematical model of openpit shovel excavator parameters optimization (MMO). In the way of optimization criterion there were used generalized estimators of engineering level, and in the way of parameters being optimized there were used its simple indicators.

$$
\left\{\begin{array}{l}
k=a_{0}+a_{1} k_{M}+a_{2} N_{n p}^{y}+a_{3} \lambda+a_{4} T_{p} \rightarrow \max \\
a_{10}+a_{11} k_{M}+a_{12} N_{n p}^{y}+a_{13} \lambda+a_{14} T_{p} \leq K_{n}^{0}+S_{0}^{K n} \\
a_{10}+a_{11} k_{M}+a_{12} N_{n p}^{y}+a_{13} \lambda+a_{14} T_{p} \geq K_{n}^{0}-S_{0}^{K n} \\
a_{20}+a_{21} k_{M}+a_{22} N_{n p}^{y}+a_{23} \lambda+a_{24} T_{p} \leq K_{M}^{0}+S_{0}^{K n} \\
a_{20}+a_{21} k_{M}+a_{22} N_{n p}^{y}+a_{23} \lambda+a_{24} T_{p} \geq K_{M}^{0}-S_{0}^{K M} \\
a_{30}+a_{31} k_{M}+a_{32} N_{n p}^{y}+a_{33} \lambda+a_{34} T_{p} \leq K_{\ni}^{0}+S_{0}^{K \ni} \\
a_{30}+a_{31} k_{M}+a_{32} N_{n p}^{y}+a_{33} \lambda+a_{34} T_{p} \geq K_{\ni}^{0}-S_{0}^{K \ni} \\
\lambda_{\max } \geq \lambda \geq \lambda_{\min } \\
k_{M} \geq 0 ; N_{n p}^{y} \geq 0 ; \lambda \geq 0 ; T_{p} \geq 0
\end{array}\right.
$$

where $\mathrm{k}$ is a composite indicator of engineering level (optimization criterion); $T_{P}-$ excavator service life, $\mathrm{h} ; k_{M}$ - specific metal content of the excavator, $\mathrm{t} / \mathrm{m}^{3} ; \lambda$ - functional criterion of open-pit shovel excavators quality, $\mathrm{kJ} / \mathrm{h} ; N_{n p}{ }^{Y}-$ specific drive power, $\mathrm{kW} / \mathrm{m}^{3}$; $K_{M}{ }^{0}, K_{E}{ }^{0}, K_{n}{ }^{0}$ - specified values of specific weight restrictions, as well as specific power consumption and indicator of productivity restrictions; $S_{0}{ }^{K N}, S_{0}{ }^{K E}, S_{0}{ }^{K M}$ - values of standard 
deviations while finding out the regressional reliance of outcome performance data on the parameters being optimized.

\begin{tabular}{|c|}
\hline Functional criterion determination $\left(\lambda_{i}\right)$ \\
\hline Simple indications of engineering level $P_{i j}$ selection and determination \\
\hline Specified indicators of engineering level $X_{i j}=P_{i j} / \lambda_{i j}$ determination \\
\hline Sample machine indicators selection \\
\hline Simple indicators of engineering level $q_{i j}=X_{j i j} / X_{i j}$ determination \\
\hline Calculation of engineering level composite indicator \\
$k_{i}=\frac{1}{(n-1) \sum_{1}^{n} q_{i j}} \sqrt{n \sum_{1}^{n}\left[q_{i j}\left(\sum_{1}^{n} q_{i j}-q_{i j}\right]^{2}\right.}$. \\
\hline
\end{tabular}

Fig. 2. The calculation algorithm of excavator composite quality indicator.

Constants of goal function models and restrictions are determined as a result of mathematical experiment realization that is understood to be calculation of composite engineering level and outcome performance data $\left(K_{M}{ }^{0}, K_{E}{ }^{0}, K_{n}{ }^{0}\right)$ subjected to specified combinations of variables according to the experiment planning matrix.

After the optimization of composite quality indicators, it is possible to synthesize the main parameters of open-pit excavators technical characteristics.

\section{Discussion}

\subsection{Comprehensive assessment of engineering level of the existing open-pit hydraulic excavators fleet}

On the grounds of the developed range of methodologies there was conducted a comprehensive assessment of engineering level of existing open-pit hydraulic «front shovel» type excavators fleet according to proposed nomenclature of simple indicators, using specific for open-pit excavators functional criterion.

Assessment of the engineering level was conducted under the following conditions: out of the whole variety of the models and modifications of open-pit excavators there were selected machines of all dimension types with shovel capacity equal to $5.2-45 \mathrm{~m}^{3}$. Almost all the excavators under discussion are produced in lots but some models were taken out of production. However, they have also been included into the group of machines under the discussion. It has been done to allow taking into consideration the previous experience of open-pit excavating equipment design as fully as it is possible.

To compare the engineering level of domestic production excavators (OMZ) with foreign equipment there were examined sufficiently proven and widely used open-pit excavators manufactured by the leading in this field companies: American "Caterpillar», Japanese «Komatsu», «Hitachi», German «Liebherr» and Swiss «Terex O\&K». 
An overall analysis of calculation results of the open-pit hydraulic excavators engineering level composite indicator shows that all these machines have this indicator higher than 0.5 . This fact confirms that the technical level of excavators is high enough. The average technical level of the group of excavators under discussion is $Y_{C P}=0.764$.

Table 1 presents the following: the higher positions in the ranked list are occupied by excavators with small bucket (shovel) - capacity. This can be explained by the fact that while increasing the machine size and complicating its design the scaling factor as well as system factors begin to come out increasingly.

Table 1. Composite indicator of open-pit excavators engineering level.

\begin{tabular}{|c|c|c|c|c|c|c|c|c|}
\hline The excavator model & $\begin{array}{l}\text { 385C } \\
\text { FS }\end{array}$ & $\begin{array}{l}\text { EG- } \\
150\end{array}$ & $\begin{array}{c}\text { 365C } \\
\text { FS }\end{array}$ & $\begin{array}{l}\text { EX } \\
1200\end{array}$ & $\begin{array}{c}\text { EX } \\
1900\end{array}$ & $\begin{array}{c}\mathrm{R} 994 \\
\text { Litronic }\end{array}$ & $\begin{array}{c}\mathrm{PC} \\
1250-7\end{array}$ & \begin{tabular}{|l|} 
R984 \\
Litronic
\end{tabular} \\
\hline Functional criterion. $\mathrm{kJ} / \mathrm{h}$ & 23.04 & 24.22 & 22.69 & 22.46 & 22.30 & 21.93 & 21.57 & 20.88 \\
\hline $\begin{array}{c}\text { Composite quality } \\
\text { indicator }\end{array}$ & 0.913 & 0.894 & 0.877 & 0.850 & 0.830 & 0.816 & 0.815 & 0.769 \\
\hline The ex & $\begin{array}{l}\text { EG - } \\
550\end{array}$ & $\begin{array}{c}\text { RH } \\
\text { 40-E }\end{array}$ & \begin{tabular}{|c|} 
PC \\
$3000-6$
\end{tabular} & $\begin{array}{l}\text { EG - } \\
350\end{array}$ & $\begin{array}{c}\text { PC } \\
4000\end{array}$ & $\begin{array}{c}\text { PC } \\
8000-6\end{array}$ & $\begin{array}{c}\text { RH } \\
90-C\end{array}$ & $\begin{array}{c}\text { RH } \\
120-E\end{array}$ \\
\hline Functional criterion. $\mathrm{kJ} / \mathrm{h}$ & 22.54 & 20.65 & 20.88 & 22.07 & 21.24 & 20.75 & 20.75 & 20.63 \\
\hline $\begin{array}{c}\text { Composite quality } \\
\text { indicator }\end{array}$ & 0.768 & 0.766 & 0.759 & 7 & 0.751 & 0.738 & 0.738 & 0.738 \\
\hline The excavator model & $\begin{array}{c}\text { R996 } \\
\text { Litronic }\end{array}$ & $\begin{array}{l}\text { RH } \\
400\end{array}$ & $\begin{array}{c}\mathbf{E X} \\
\mathbf{5 5 0 0}\end{array}$ & $\begin{array}{c}\mathrm{R} 995 \\
\text { Litronic }\end{array}$ & $\begin{array}{c}\text { EX } \\
3600\end{array}$ & $\begin{array}{l}\text { EG - } \\
110\end{array}$ & $\begin{array}{c}\text { RH } \\
200-E\end{array}$ & $\begin{array}{c}\text { EG - } \\
5.5\end{array}$ \\
\hline Functional criterion. $\mathrm{kJ} / \mathrm{h}$ & 21.54 & 21.68 & 21.24 & 20.68 & 20.47 & 21.50 & 19.85 & 19.58 \\
\hline $\begin{array}{c}\text { Composite quality } \\
\text { indicator }\end{array}$ & 0.736 & 0.730 & 0.728 & 0.708 & 0.704 & 0.700 & 0.647 & 0.616 \\
\hline
\end{tabular}

If to examine the engineering level of the machines produced by foreign manufacturers, the companies Caterpillar and Hitachi should be put emphasis on because the machines produced by them have higher than average engineering level. The machines manufactured by Terex have the lowest indicator of engineering level. The average engineering level of domestic machines is slightly below the level of excavators produced by foreign companies. The indicator value $Y$ expressing the averaged values of the engineering level composite indicator for foreign machines under discussion is $Y_{\text {foreign }}=0.769$, that is $3 \%$ higher than for excavators produced by domestic company OMZ, for which $Y_{\text {domestic }}=$ 0.747. However, domestic machines have $Y$-indicator $3.2 \%$ higher than the machines produced by Terex Company. This means that from the point of view of construction arrangement perfection and of new ideas and solutions existence, excavators produced by Russian manufactures almost keep a pace with foreign machines. It should be also mentioned that domestic excavators EG150 and EG550 occupy the 2 and 9 lines in the ranking list correspondingly (table 1). However, other models are at the bottom of the list that dramatically reduces the average value of the indicator.

High quality of the excavators manufactured by foreign companies is mainly achieved by a longer service life (more than 90 thousand hours), higher maintenance and operation efficiency, which, in its turn, is caused by the appliance of up-to-date methods and design tools, extensive use of advanced production technologies and construction materials, modern control and diagnostics systems as well the latest achievements of ergonomics and design [6, 12-14].

The main directions of improving the open-pit hydraulic excavators engineering level are the following: increasing the specific digging force, reducing the specific metal content and energy density. The main directions of domestic machines improvement are the following: increasing service life and reliability of excavators by the hydraulic drive design 
improvement, as well as widening the hydraulic excavators range by means of manufacturing bigger dimension-types [15-18].

\subsection{Open-pit excavator parameters optimization at the stage of developing its technical design specifications}

Having the optimum values of optimized indicators $\lambda^{*}, N_{n p}{ }^{y^{*}}, k_{M}{ }^{*}$ и $T_{p}{ }^{*}$ as well as the engineering level composite indicator $k^{*}$ that are determined by the relation (8), it is possible to determine the basic parameters of the open-pit excavator's technical characteristics.

The results of optimal parameters synthesis for excavator with bucket (shovel) capacity equal to $15 \mathrm{~m}^{3}$ and technical characteristics of its analogue are presented in table 2 .

Table 2. The results of optimal parameters synthesis.

\begin{tabular}{|l|c|c|}
\hline \multicolumn{1}{|c|}{ Parameters } & $\begin{array}{c}\text { KOMATSU } \\
\text { PC-3000-6 }\end{array}$ & $\begin{array}{c}\text { Parameter optimum } \\
\text { value }\end{array}$ \\
\hline Excavator bucket capacity $\left(E_{\kappa}\right), \mathrm{m}^{3}$ & 15 & 15 \\
\hline Operating weight $\left(G_{E}\right), \mathrm{t}$ & 253 & 224.3 \\
\hline Drive power $\left(N_{n p}\right), \mathrm{kW}$ & 940 & 949.5 \\
\hline Estimated cycle time $\left(t_{c}\right), \mathrm{s}$ & 26 & 23.4 \\
\hline Travel speed $\left(v_{E}\right), \mathrm{km} / \mathrm{h}$ & 2.4 & 2.7 \\
\hline Maximum digging radius $\left(R_{\kappa}\right), \mathrm{m}$ & 13.5 & 14.6 \\
\hline Maximum unloading radius $\left(R_{B}\right), \mathrm{m}$ & 10.94 & 12.4 \\
\hline Maximum digging height $\left(h_{\kappa}\right), \mathrm{m}$ & 14.7 & 15.1 \\
\hline Maximum unloading height $\left(h_{B}\right), \mathrm{m}$ & 10.2 & 11.1 \\
\hline Maximum digging force $\left(P_{\kappa o n}\right), \mathrm{kN}$ & 1100 & 993.3 \\
\hline Service life $\left(T_{p}\right)$, thousand hours & 90 & 84.5 \\
\hline Swing speed $(n)$, rpm & 4.6 & 4.8 \\
\hline Bucket raise speed $\left(V_{r}\right), \mathrm{m} / \mathrm{s}$ & 0.78 & 0.91 \\
\hline Composite indicator of engineering level $k$ & 0.759 & 0.981 \\
\hline
\end{tabular}

\section{Conclusion}

The research work contains a new solution of the recent scientific problem of parameters optimization for open-pit shovel excavators with the purpose to select and create machines of higher engineering level which is essential for the development of mining machines design and operation theory and practice.

The proposed methodology of the optimal selection and parameters optimization of open-pit shovel excavator models will allow performing science-based selection of excavators possessing optimum for the specified conditions parameters as well as will make it possible to install and optimally coordinate their parameters upon specified criteria at the design stage.

The was performed a comprehensive assessment of the engineering level of open-pit hydraulic «front shovel» type excavators existing fleet that use the software package, the engineering level of the open-pit excavators existing fleet was evaluated, the ways to increase the engineering level and methods of their realization at the stage of design were found out.

As a result of studying optimization mathematical model there were determined the optimal values of composite quality indicators out of which the basic parameters of the technical characteristics of open-pit excavators were synthesized. For example, there were examined the parameters of the excavator KOMATSU PC-3000-6 and of an excavator with 
optimal parameters (table 2) and what is more, the composite quality indicator of the latter is $30 \%$ higher.

The range of methodologies and software package can be used by mining enterprises as a basis for selecting the most suitable for their conditions machine models and development of technical specifications for their design. Selection of an optimum excavator model will make it possible to reduce expenses that are caused by production loss in case of its unreasonable selection.

\section{References}

1. S. Er, M. Yilmaz, A. Ertin, A. Tugrul, N. Tokgöz, J. Geol. Soc. India, 89, 5 (2017)

2. S. Fiscor, Eng. and Mining J., 210, 3 (2009)

3. J. Yan, B. Li, G. Guo, Y. Zeng, M. Zhang, Chin. J. Mech. Eng., 26, 6 (2013)

4. S. Frimpong, Y. Hu, H. Inyang, Int. J. Geomech., 8, 1 (2008)

5. K. Awuah-Offei, S. Frimpong, Mech. and Mach. Theory, 42, 8 (2007)

6. T. Yoshida, T. Koizumi, N. Tsujiuchi, K. Chen, Y. Nakamoto, Trans. Jap. Soc. Mech. Eng. C., 78, 787 (2012)

7. H. Wang, M. Sun, Z. He, S. Huang, F. Rong, X. Yuan, J. Hunan Univ. Natur. Sci., 45, 2 (2018)

8. Y.-g. Wang, Q. Fang, Coal Mine Mach., 27, 11 (2006)

9. O. J. Abdel-baqi, A. Nasiri, P. J. Miller, IEEE Trans. Ind. Appl., 52, 6 (2016)

I. Mitsuhashi, H. Tsukamoto, N. Sakai, Sumitomo Heavy Ind. Techn. Rev., 165, 7 (2007)

10. H. F. Bilgin, M. Ermis, K. N. Kose, I. Cadrici, A. Acik, T. Demirci, A. Terciyanli, C. Kocak, M. Yorukoglu, IEEE Trans. Ind. Appl., 43, 1 (2007)

11. J. E. Fernández, R. Vijande, R. Tucho, J. Rodríguez, A. Martín, Wear, 250, 1 (2001)

12. C. Dogruoz, N. Bolukbasi, Bull. Eng. Geol. and Environ, 73, 3 (2014)

13. Y. Cao, Y. Xie, Nonlinear Dyn., 91, 1 (2018)

14. O. Litvin, M. Tyulenev, S. Zhironkin, S. Prokopenko, Acta Montanistica Slovaca, 22:2, 146-152 (2017)

15. E.A. Tyuleneva, Yu.V. Lesin, Ya.O. Litvin, Journal of Mining and Geotechnical Engineering, 1(4), 35-49 (2019). DOI: 10.26730/2618-7434-2019-1-35-49

16. M. Tyulenev, O. Litvin, M. Cehlár, S. Zhironkin, M. Gasanov, Acta Montanistica Slovaca, 22:3, 296-302 (2017)

17. M. Tyulenev, O. Litvin, S. Zhironkin, M. Gasanov, Acta Montanistica Slovaca, 24(2), 88-97 (2019)

18. M.A. Tyulenev, S.A. Zhironkin, E.A. Garina, Int. J. Min. Miner. Eng., 7:4, 363-370 (2016) 